\title{
First-Year Exploratory Studies about Students' Career Decision Processes and the Impact of Data-Driven Decision Making
}

\author{
Tugba Karabiyik ${ }^{1, *}$, Dominic Kao ${ }^{2}$, Alejandra J. Magana ${ }^{2}$ \\ ${ }^{1}$ Purdue Systems Collaboratory, Purdue University, West Lafayette, Indiana, USA. \\ ${ }^{2}$ Department of Computer and Information Technology, Purdue University, West Lafayette, Indiana, USA.
}

\begin{abstract}
How to cite this paper: Tugba Karabiyik, Dominic Kao, Alejandra J. Magana. (2021). First-Year Exploratory Studies about Students' Career Decision Processes and the Impact of Data-Driven Decision Making. The Educational Review, USA 5(11), 418-433.

DOI: 10.26855/er.2021.11.003
\end{abstract}

Received: October 7, 2021

Accepted: October 30, 2021

Published: November 26, 2021

Corresponding author: Tugba Karabiyik, Purdue Systems Collaboratory, Purdue University, West Lafayette, Indiana, USA.

Email: tkarabiy@purdue.edu

\begin{abstract}
Career choice is one of the most crucial and challenging decisions that young adults need to make. Institutions have implemented strategies (such as first-year exploratory studies) which can provide students guidance to explore multiple majors. One strategy that has not been explored as a guidance to help students prepare is the use of historical data on specific majors. This study investigates the feasibility of using historical data from previous graduating classes. We presented students with personalized career-related data for their top two choices for university majors and observed the impact of exploring this data on career related perceptions, intentions, and decisions. Students were compared on career learning competences, career exploratory plans and intentions, career exploration strategies, and career learning before and after the intervention. Our results suggest that engaging students in exploring career-related historical data, regardless of the format, has a significantly positive effect on their career learning and exploration.
\end{abstract}

\section{Keywords}

Data-Driven Decision Making, Career Exploration, Career Intentions, Career Decision Making, Career Learning

\section{Introduction}

Career choice is a very crucial task for undergraduate students since it affects their entire future. It is also a challenging task, especially in a technological era, with the availability of multiple career paths and opportunities as well as higher job competition (Chaudhary et al., 2019). According to the Council of Scientific and Industrial Research (CSIR), about $40 \%$ of students are confused about their career options (Chaudhary et al., 2019). Students graduating from high school often have very limited or vague information about university majors (Grant, 2019). Many students are educationally and vocationally undecided for career decision-making, even those that are already pursuing their higher education (Lewallen, 1995). About one-third of first-time college students change their majors in their first three years in college at least once (Leu, 2017). Students in Science, Technology, Engineering, and Mathematics (STEM) programs are surprisingly more likely than those in non-STEM fields (35 vs. 29 percent) to change majors (Lederman, 2018). The problem may get worse after graduation from college (Jelks \& Crain, 2020). Two-thirds of college graduates struggle to launch their careers (Selingo, 2016). It is suggested that choosing and deciding on the right career before entering the job market increases both productivity and satisfaction in life (Olamide \& Olawaiye, 2013). Therefore, there is a need to 
guide students in career exploration and career decision-making to improve their career development (Verma et al., 2017). Career advising is one way to help students understand how their academic and personal interests, abilities, and values might be related to the career that they are thinking of and how to shape their educational and career goals accordingly (Gordon, 2006). Career counseling, however, often uses a more traditional approach for guiding students consisting of career self-assessments based on aptitudes and preferences. Such practices help students understand themselves and the types of work aligned to their priorities (Schiersmann et al., 2012). Many online and face-to-face career decision-making courses have also been efficient in aiding students' career decision-making (Fouad et al., 2009).

Another career decision-making approach used once students have started their college studies is university-level exploratory studies programs. Exploratory studies allow students to explore, search, and find their careers (Workman, 2015). Specifically, exploratory studies programs enable undecided students to learn about their strengths, interests, and skills and aim to help students select a major that is right for them-a lengthy process that takes up to four semesters. Even though students get help in career decision making through career advising, courses, school counseling, mentorship programs, first-year exploratory studies, and parents' and peers' suggestions (Gordon \& Steele, 2015; Hooley, 2012; Kezar \& Gehrke, 2016; Kirkner \& Levinson, 2012; Savickas, 2019; Workman, 2015) due to the inherent complexity involved in career decision-making, students still have difficulty making their career decisions.

An approach that could aid in the career decision-making process relates to the use of career-related data on specific majors. Career-related data and information about the majors from previous graduating classes could inform students in their decision-making process. Specifically, career-related data visualizations, which refer to information about the majors using maps, graphs, tables, etc., can provide much-needed guidance to students on their future career journey. Towards this goal, we aim to understand how undergraduate college students used visualizations of historical post-graduation data on specific majors, either in a graph form or a table form, to inform themselves about career exploration and their future careers after graduation. This study investigates the feasibility of using historical data from career outcome information from previous graduating classes as a strategy to support data-driven decision-making in career choice among first-year exploratory studies students. The research question was: What is the impact of historical career outcome information on first-year exploratory studies students' career learning competences, career exploratory plans and intentions, and career exploration strategies?

\section{Background}

Young adults should be guided to make their best decision regarding their career choice. Some supporting career decision-making strategies include career advising, career counseling, career decision-making courses, first-year exploratory studies programs, and peer's and parents' support. Career advising is one of the most effective strategies in career choice and career decision-making (Gordon et al., 2011; Gordon \& Steele, 2015). Career advising aims to help students understand their interests to make career decisions accordingly (Gordon, 2006).

Career counseling is another type of supporting strategy provided by career counselors to their clients, including young adults (Athanasou \& Van Esbroeck, 2008; Brown \& Brown, 2012). More specifically, school career counselors aim to help students explore their interests and abilities through self-assessment and provide them information about the colleges, majors, and jobs as needed. They evaluate students' backgrounds, education, and training to develop realistic goals to make the right career decisions (Gati et al., 1996). Even though career counseling is an effective strategy for career-decision making, it is not enough by itself to help students overcome career decision-making difficulties and complexities.

Another approach relates to online or face-to-face career decision-making courses. These courses aim to increase students' career-decision-making confidence and ease career exploration (Fouad et al., 2009). Research shows that career decision-making courses can improve students' foresight and reduce their decisional difficulties in their careers (Savickas, 1990). Also, students who complete a career decision-making course often show an increased career decision-making self-efficacy in obtaining occupational information, setting career goals, and career planning. Career courses also lower perceived career decision difficulties (Reese \& Miller, 2006).

Undecided first-year students also have a chance to make career decisions in college through first-year exploratory studies programs where they get extensive academic and career advising (Gordon \& Steele, 2015; Workman, 2015). Exploratory studies aim to help students explore their strengths, interests, and skills through personality tests and discover the careers that fit their personality type. Students in exploratory studies programs have an individualized career advisor who guides them on how to search for majors and facilitates interviews with students from majors to have a smooth transition to a major. One strategy that can be coupled with exploratory studies is the use of historical data of career outcome information from previous graduating classes. Historical data could inform students in their decision-making process. Therefore, we propose using historical post-graduation data from career outcome information 
from as a strategy to support data-driven decision-making for students in career choice.

Data analytics is a critical practice that helps to analyze raw data. As we gain insights from the data, we can make strategic decisions based on the data. This is called data-driven decision-making (DDDM). DDDM is the practice of basing decisions on the analysis of the data rather than purely on intuition. Recently, DDDM garners researchers' and company leaders' attention more than ever (Provost \& Fawcett, 2013). DDDM aims to systematically collect data, analyze it, and guide a range of decisions to increase success and to learn in life (Ikemoto \& Marsh, 2007). DDDM applications in career exploration are relatively new, and only little has been done so far.

For instance, historical post-graduation data has been used to forecast students' career choices (Nie et al., 2016). Nie (2016) proposed a data-driven framework to predict students' career choice of graduation based on their behavior in and around the campus. They found that the extracted professional skills, behavior regularity, and economic status were significantly correlated with career choices. In a more recent study, an interactive visualization tool helped in career education for high school and first-year college students ( $\mathrm{Li}$ et al., 2018). This approach aimed to represent the variety of majors and pathways to the occupations using recent years' job placement data from university students. Balasubramanyam et al. (2018) developed a decision-making system that offered students suggestions for career decision-making based on student specifications of jobs they were interested in. They made a comparison between the results suggested by their software and a human counselor. Investigators found that their software system was more efficient than manual counseling, which often takes more time to interact with students and offers more career choice advice (Balasubramanyam et al., 2018). Even though DDDM has an enormous potential to be used in career decision-making, it has not been used to investigate how students make career planning and selection based on data visualizations and dashboards.

\subsection{Theoretical Framework and Implications for the Study}

The theoretical foundation for this study was the diffusion of innovations (Rogers, 1962; Rogers, 2010). The diffusion of innovations theory aims to explain the method, reason, and spread rate of new ideas or technology. Rogers (1962) defined diffusion as the process by which an innovation is adopted through communication channels over time among the participants in a social system. According to Rogers (1962), innovation can be described as a new idea, behavior, or product. For our study, students' career choice was operationalized as an innovation as it refers to the selection of a particular path or vocation in terms of career. This selection process is similar to the stages of the diffusion of innovation; it is accomplished through an awareness stage, a persuasion stage, followed by a decision stage to adopt or reject the innovation. Diffusion of innovation theory has been applied to many disciplines, from communications, marketing, development studies, health promotion, organizational studies, medical sociology, knowledge management, biology to complexity science (Mahajan, 2010; Mascia \& Mills, 2018). The comprehensiveness of diffusion of innovation theory has led to investigations on the characteristics of innovations, individual adopters, organizations, and the process and rate of innovation adoption. In this study, we operationalize career decisions as innovation and leverage the process of adopting innovations to investigate career decision-making processes.

According to Rogers (2010), adopting innovation is similar to a decision-making process. Under this framework, the decision-making process consists of five steps: (1) awareness, where the individual is first exposed to the innovation; (2) persuasion, where the individual actively seeks for information related to the innovation; (3) decision, where the individual evaluates the advantages and disadvantages of the innovation based on some evidence and makes a decision; (4) implementation, where the individual engages with the innovation and determines the usefulness of the innovation; and (5) confirmation, where the individual finalizes the decision-making process by continuing to use/pursue the innovation.

The implications of using diffusion of innovations as the study's theoretical framework relate to the operationalization and measurement of some of the five-step decision-making process stages. Specifically, this study focuses on the first three steps of the diffusion of the innovation decision-making process. For this, existing scales were used for measuring the different stages of the decision-making process. Table 1 presents an alignment between the three first stages of the diffusion of the innovation decision-making process and the scales adopted for measuring them, along with our justification.

\section{Methods}

To approach the research question investigating the effectiveness of the use of historical post-graduation data regarding salary, employers, employment locations, and continuing education by degree and major from previous graduating classes to aid students' career decision processes. For this, we conducted a randomized controlled trial. Participants were randomly assigned to one of two intervention conditions: half of the students were exposed to personalized career-related data visualizations, including bar charts, pie charts, and maps, while the other half of the students were ex- 
posed to career-related data through tables. Before and after the intervention, pre- and post-test questionnaires were administered to measure the change in perceptions of career learning competences (PCLC), career exploratory plans and intensions (CEPI), career exploration survey (CES), perceptions of the learning experience (PLE), and major preference ranking survey (MPRS). The effects of the interventions were compared between both conditions and between pre-and post-test. Data were analyzed using both descriptive and inferential statistics.

Table 1. Alignment between constructs and measures of the study and the selected stages of the diffusion of the innovation decision-making process

\begin{tabular}{|c|c|c|c|}
\hline \multicolumn{2}{|c|}{ Rogers' Stages of the Adoption Process } & \multicolumn{2}{|c|}{ Adaptation of the Stages for the Study } \\
\hline Stage & Definition & Scale & Definition \\
\hline Awareness & $\begin{array}{l}\text { The individual is first exposed to the } \\
\text { innovation. }\end{array}$ & $\begin{array}{l}\text { Perceptions of career } \\
\text { learning competences } \\
\text { (PCLC) }\end{array}$ & $\begin{array}{c}\text { The student is first exposed to a new } \\
\text { career decision opportunity. Student's } \\
\text { career-related learning competences are } \\
\text { initially assessed. }\end{array}$ \\
\hline Persuasion & $\begin{array}{l}\text { The individual actively seeks infor- } \\
\text { mation related to the innovation. }\end{array}$ & $\begin{array}{l}\text { Career Exploratory } \\
\text { Plans or Intentions } \\
\text { (CEPI) and Career Ex- } \\
\text { ploration Survey (CES) }\end{array}$ & $\begin{array}{c}\text { The student reports on their level of } \\
\text { commitment in career exploration and } \\
\text { actively seeks related information and } \\
\text { help. }\end{array}$ \\
\hline Decision & $\begin{array}{l}\text { The individual evaluates the advan- } \\
\text { tages and disadvantages of the inno- } \\
\text { vation based on some evidences and } \\
\text { makes a decision. }\end{array}$ & $\begin{array}{l}\text { Perceptions of Career } \\
\text { Learning (PCL) and } \\
\text { Major Preference Rank- } \\
\text { ing Survey (MPRS) }\end{array}$ & $\begin{array}{l}\text { Once the student explores all ca- } \\
\text { reer-related information, the student } \\
\text { makes a major choice and reflects on } \\
\text { their experiences. }\end{array}$ \\
\hline
\end{tabular}

\subsection{Participants}

Participants of this study were 30 first-year undergraduate exploratory studies students from the United States of America who had not decided on their majors at the time of the study. Students were volunteered to participate the study. 11 of them were men, and 19 were women. 23 of the students were 18 years old, and 7 of them were 19 years old. In terms of ethnicity, 21 of the students were White, 3 were Asian, 3 were Latino, 2 African American and one was bi-racial. These students were invited to participate in a voluntary hour-long study. At the recruitment time, students were asked to identify their top two majors as career choices (Please see appendix 2 for students' preferred two majors). Based on that students' preferred two majors related data visualizations were created.

\subsection{Historical career outcome information and conditions}

This study' historical post-graduation data consisting of salary, employers, employment locations, and continuing education by degree and major from previous graduating classes was obtained from Purdue University Center for Career Opportunities' open-source post-graduate data and surveys. The data were self-reported and only represented graduates' information from the selected majors. All participants in this study observed and learned information about their top two career choices for university majors through 10 different individually prepared data visualizations or tables. Data represented trends within the last five years of graduation showing (1) the percentage of students seeking education, seeking employment, continuing education, employed, or others; (2) average salaries over the last five years; (3) average salaries of master's degree graduates; (4) average salaries compared by degree level; (5) most preferred graduate school locations by graduates; (6) employment locations by the state during the year 2018, which was the most recent data they had; (7) most preferred occupational areas during the year 2018; (8) number of internships they had during 2018; (9) first 25 employers that class of 2018 students was working with; and (10) finally data about the composite cost of living index during the first quarter of 2019 showing the cost of living index for all of the states in the USA.

Data were presented either in a graph or a table format representing the same information (see Figure 1 and Table 2). Each student saw personalized data visualizations or tables for two different preferred majors, which they identified at the recruitment stage during the intervention. Students could see all of the 10 data visualizations/tables side-by-side to compare the two preferred majors and eight college-related information easily.

\subsection{Procedures}

The study was carried out with one student at a time. The entire protocol took only one session that lasted for an hour. We prepared all the personalized graphs or tables for the chosen majors in advance. The graph group was given perso- 
nalized career-related data visualizations in bar charts, maps, and pie charts to learn more about the majors they thought of pursuing careers. The table group also observed the same career-related data in a table format.

When students came into the session, they were first given time to read and sign the consent form. After that, they were given a pretest questionnaire followed by introducing students personalized career-related graphs or tables. In the meantime, a concurrent think-aloud protocol that asks students to verbalize their thinking was conducted (Jääskeläinen, 2002). After observing and comparing the given graphs or tables, students were given a post-test questionnaire. Finally, the study was closed with an exit interview where open-ended questions were asked to investigate students' views of the learning experience and the study in general. The data set used in this study was based on students' pre-and post-test results and audio-recorded transcriptions.

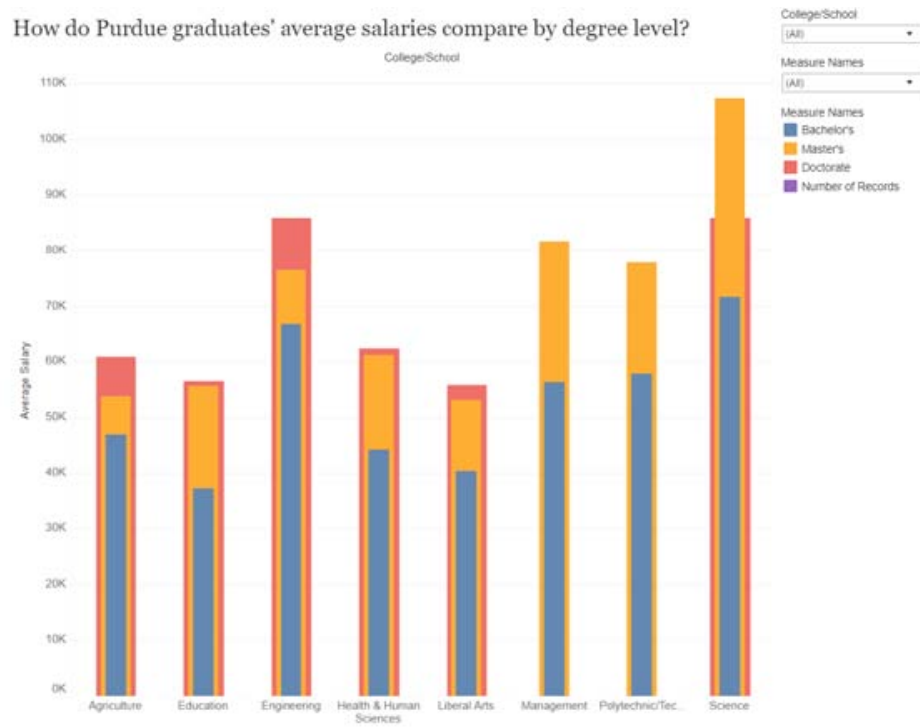

Figure 1. Purdue University 2018 graduates' average salaries are shown by degree level through data visualization.

Table 2. Purdue University 2018 graduates' average salaries are shown by degree level through the table

\begin{tabular}{|c|c|c|}
\hline \multicolumn{3}{|c|}{ How do Purdue graduates’ average salaries compare by degree level? } \\
\hline College/School & Degree Level & Average Salary \\
\hline \multirow{3}{*}{ Agriculture } & Bachelor's & $\$ 46,977$ \\
\hline & Master’s & $\$ 53,883$ \\
\hline & Doctorate & $\$ 60,834$ \\
\hline \multirow{3}{*}{ Education } & Bachelor’s & $\$ 37,227$ \\
\hline & Master’s & $\$ 55,634$ \\
\hline & Doctorate & $\$ 56,571$ \\
\hline \multirow{3}{*}{ Engineering } & Bachelor’s & $\$ 66,665$ \\
\hline & Master’s & $\$ 76,407$ \\
\hline & Doctorate & $\$ 85,855$ \\
\hline \multirow{3}{*}{ Health \& Human Sciences } & Bachelor's & $\$ 44,200$ \\
\hline & Master’s & $\$ 61,167$ \\
\hline & Doctorate & $\$ 62,355$ \\
\hline \multirow{3}{*}{ Liberal Arts } & Bachelor's & $\$ 40,431$ \\
\hline & Master’s & $\$ 53,209$ \\
\hline & Doctorate & $\$ 55,878$ \\
\hline \multirow{2}{*}{ Management } & Bachelor’s & $\$ 56,379$ \\
\hline & Master’s & $\$ 81,634$ \\
\hline \multirow{2}{*}{ Polytechnic/Tech } & Bachelor's & $\$ 57,792$ \\
\hline & Master’s & $\$ 77,774$ \\
\hline \multirow{2}{*}{ Science } & Bachelor's & $\$ 71,571$ \\
\hline & Master’s & $\$ 107,309$ \\
\hline
\end{tabular}




\subsection{Data Collection Method}

Students were asked to score their perceptions of four types of outcome measures mapped to the three stages of the adoption process. As shown in Table 1, scales used to measure preparedness in the awareness stage included perceptions of career learning competences (PCLC). Scales used for measuring preparedness in the persuasion stage had career exploratory plans or intentions (CEPI) and career exploration survey (CES). Scales using for measuring preparedness in the decision stage included perceptions of career learning (PCL) and major preference ranking survey (MPRS). We collected pre-and post-test data using the Qualtrics survey tool, including Likert scale questions with the scales (see Appendices). Besides, we audio-recorded the intervention process to understand the depth of the data. At the end of the study, we also asked students questions that evaluated the information they received and the overall learning experience.

\subsubsection{Awareness Stage}

The awareness stage was operationalized as the process where students first evaluate their preparedness for engaging in career exploration. For measuring awareness, we used the Perceptions of Career Learning Competences (PCLC) scale. The PCLC is a 10-item scale (see Appendix 1, Section A) where students were asked to evaluate their career-related learning competences (Hummel et al., 2018). It uses a 5-point response continuum ranging from 1 (I really disagree with this statement) to 5 (I really agree with this statement). These questions measure students' awareness of their career-related interests and skills. Specifically, it reports on the perceived importance of engaging in career exploration, self-knowledge of interests and skills, and preferences and interests in occupation, among others.

\subsubsection{Persuasion Stage}

The persuasion stage was operationalized as the process where students report on their commitment to career exploration and actively seek related information and help. For measuring persuasion, we used two scales: the Career Exploratory Plans or Intensions (CEPI) (Betz \& Voyten, 1997) and the Career Exploration Survey (CES) (Stumpf et al., 1983). CEPI is a 5-item scale (see Appendix 1, Section B) measuring students' career plans and intentions (Betz \& Voyten, 1997). This scale uses a 5-point response continuum ranging from 1 (I really disagree with this statement) to 5 (I really agree with this statement). This scale measures students' intentions for engaging in career exploration and plans to seek career-related information actively. CES is a multi-section scale (see Appendix 1, Section C) with four subscales included (Stumpf et al., 1983). These are environment exploration, which measures the students' intention of investigating career-related information with 6 items using a 5-point response continuum ranging from 1 (little) to 5 (a great deal), focus, which measures how sure are the students about their career choices with 5 items using a 5-point response continuum ranging from 1 (not too sure) to 5 (Very sure), satisfaction with information, which measures the students' satisfaction with the career-related information they have with 6 items using a 5-point response continuum ranging from 1 (Not satisfied) to 5 (Very satisfied) and decisional stress, which measures the level of stress about career decisions with 4 items using a 7-point response continuum ranging from 1 (Insignificant compared to other issues with which I have had to contend) to 7 (One of the most stressful issues with which I have had to contend).

\subsubsection{Decision Stage}

The decision stage was operationalized as the process where students explored all career-related information, made a major choice, and reflected on their experience. We used two instruments for measuring decisions: the Perceptions of Career Learning (PCL) scale, and the other was the major preference ranking survey (MPRS). The PCL is a 7-item scale (see Appendix 1, Section D) measuring students' views regarding learning about careers (Hummel et al., 2018). It uses a 5-point response continuum ranging from 1 (I really disagree with this statement) to 5 (I really agree with this statement). The MPRS consisted of two questions that asked students to write down up to four majors and occupational areas that they wanted to pursue and then rank those choices before and after the intervention.

\subsection{Data Analysis Method}

Quantitative data were gathered through Qualtrics pre-and post-test surveys. Data were downloaded in excel file format, cleaned, and prepared to be analyzed using SPSS version 25. Descriptive statistics were used to identify measures of central tendency and spread. Inferential statistics (paired t-tests) were used to identify learning gains after the intervention. The higher averages (4: I agree with this statement, and 5: I strongly agree with this statement) on scores for the PLCL, CEPI, CES (except decisional stress subscale), and PLE, and lower averages on scores for the CES decisional stress subscale were interpreted as more positive outcomes.

All questionnaire items within the same subscale had the same positive or negative direction when calculating the 
averages. Specifically, all four negatively phrased items in the CES decisional stress subscale, 2 items in PCL, and 4 items in PLE were reverse-coded.

\section{Results}

This section shows our findings on the impact of historical post-graduation data on students' career learning competences in the awareness stage, career exploratory plans and intentions, and career exploration survey in the persuasion stage, as well as the differences in career learning in the decision stage and perceptions of the impact, usability, and usefulness of the career outcome information.

\subsection{Awareness Stage}

In their awareness stage, students reported on their preparedness for engaging in the process of career exploration. Table 3 summarizes the descriptive statistics before and after the intervention.

Table 3. Awareness as preparedness for engaging in the process of career exploration by group

\begin{tabular}{ccccccccc}
\hline Time & \multicolumn{4}{c}{ Pretest } & \multicolumn{3}{c}{ Post-test } \\
\hline Condition & Graphs $(\mathrm{n}=15)$ & \multicolumn{2}{c}{ Tables (n=15) } & Graphs (n=15) & \multicolumn{2}{c}{ Tables (n=15) } \\
Item & $\mathrm{M}$ & $\mathrm{SD}$ & $\mathrm{M}$ & $\mathrm{SD}$ & $\mathrm{M}$ & $\mathrm{SD}$ & $\mathrm{M}$ & SD \\
\hline A1. FindingCareerInfo & 4.53 & 0.52 & 4.67 & 0.62 & 4.47 & 0.49 & 4.80 & 0.56 \\
A2. KnowLeisure & 4.27 & 0.59 & 4.40 & 0.63 & 4.40 & 0.51 & 4.47 & 0.74 \\
A3. KnowSubjects & 4.27 & 0.70 & 3.87 & 0.92 & 4.20 & 0.77 & 4.20 & 0.77 \\
A4. KnowCareerValues & 4.07 & 0.70 & 4.00 & 1.07 & 4.00 & 0.76 & 4.27 & 0.70 \\
A5. EvaluateJobSkills & 3.60 & 0.91 & 3.80 & 0.94 & 3.93 & 0.59 & 4.13 & 0.64 \\
A6. KnowAttributes & 3.80 & 0.56 & 3.60 & 1.12 & 4.00 & 0.65 & 3.93 & 0.96 \\
A7. UnderstandJobs & 3.68 & 0.83 & 3.33 & 1.11 & 4.13 & 0.35 & 3.93 \\
A8. UnderstandPeople & 3.73 & 0.80 & 3.73 & 0.80 & 3.93 & 0.80 & 3.73 \\
A9. EvaluateAdvice & 4.07 & 0.59 & 3.93 & 0.80 & 4.47 & 0.52 & 4.40 \\
A10. MatchJobInterest & 4.53 & 0.52 & 4.87 & 0.35 & 4.47 & 0.52 & 4.73 & 0.63 \\
\hline
\end{tabular}

Students agreed that it was important for them to find information about careers on average regarding students' perceptions of career learning competencies in the awareness stage. Students also agreed that having appropriate knowledge of their leisure activities, preferred school subjects, and preferred career values that match the jobs they would like to do in the future were important. Students from both groups admitted the significance of evaluating their job-related skills and career-related personal attributes and the importance of finding a job that matches their interests.

A paired-sample t-test was conducted to compare pretest and post-test mean scores for all participants in PCLP as the awareness stage. Overall, there was significant difference in scores between pre-test $(\mathrm{M}=4.033, \mathrm{SD}=0.37)$ and post-test $(\mathrm{M}=4.24, \mathrm{SD}=0.42)$ of PCLC with $\mathrm{t}(29)=-4.003, \mathrm{p}=.000$. These results show that using historical career data, regardless of the format, affects students' awareness about their preparedness for career-related interests and skills. Specifically, our results suggest that when students engaged with historical post-graduation data, their preparedness in the awareness stage for engaging in the process of career exploration was increased. Using independent samples t-test in PCLP as awareness, we found no significant differences between the groups of graphs and tables for pretest and post-test mean scores.

\subsection{Persuasion Stage}

Students reported on their level of commitment in career exploration and actively seeking related information and help in the persuasion stage. Table 4 summarizes the descriptive statistics regarding students' career exploration plans and intentions (P1 to P5) and career exploration for investigating career-related information.

In terms of students' career exploratory plans and intentions in the persuasion stage, students acknowledged that it 
was vital to spend more time learning about careers and have a plan of connecting with lots of people, including advisors and counselors in the college talk about careers. Students also found that it was essential to explore their abilities and interests and get the education needed to make a career decision.

Table 4. Persuasion as career exploratory plans and intentions (first 5 items) and as career exploration survey (P6 to P26) by group

\begin{tabular}{|c|c|c|c|c|c|c|c|c|}
\hline \multirow{3}{*}{$\begin{array}{c}\text { Time } \\
\text { Condition } \\
\text { Item }\end{array}$} & \multicolumn{4}{|c|}{ Pretest } & \multicolumn{4}{|c|}{ Post-test } \\
\hline & \multicolumn{2}{|c|}{ Graphs (n=15) } & \multicolumn{2}{|c|}{ Tables $(n=15)$} & \multicolumn{2}{|c|}{ Graphs (n=15) } & \multicolumn{2}{|c|}{ Tables $(n=15)$} \\
\hline & M & SD & M & SD & M & SD & M & SD \\
\hline P1.IntendLearningCareers & 4.33 & 0.62 & 3.87 & 1.13 & 4.47 & 0.64 & 4.53 & 0.64 \\
\hline P2.PlanTalkingPeople & 3.87 & 0.99 & 3.47 & 0.83 & 4.47 & 0.64 & 3.80 & 0.94 \\
\hline P3.CommitLearningAbilities & 4.60 & 0.51 & 4.33 & 0.90 & 4.53 & 0.52 & 4.60 & 0.51 \\
\hline P4.IntendGettingEducation & 4.80 & 0.41 & 4.87 & 0.35 & 4.73 & 0.46 & 4.80 & 0.41 \\
\hline P5.PlanTalkingAdvisors & 4.67 & 0.49 & 4.73 & 0.59 & 4.67 & 0.49 & 4.73 & 0.46 \\
\hline P6.InvestigateCareers & 4.20 & 0.77 & 4.13 & 0.92 & 4.20 & 0.68 & 4.47 & 0.83 \\
\hline P7.GoCareerPrograms & 3.67 & 0.98 & 2.67 & 1.35 & 3.93 & 1.03 & 3.07 & 1.33 \\
\hline P8.ObtainJobInformation & 3.73 & 1.03 & 3.33 & 1.29 & 4.20 & 0.77 & 3.53 & 1.36 \\
\hline P9.InitateConversations & 3.73 & 1.10 & 3.33 & 1.05 & 4.20 & 1.15 & 3.73 & 1.16 \\
\hline P10.ObtainLaborMarketInfo & 3.80 & 1.15 & 3.47 & 1.06 & 4.20 & 0.94 & 3.93 & 1.16 \\
\hline P11.SeekCareerInterestInfo & 3.87 & 0.83 & 3.93 & 1.03 & 4.33 & 0.49 & 4.40 & 0.83 \\
\hline P12.KnowJobTypes & 3.00 & 0.85 & 3.13 & 1.25 & 3.20 & 1.01 & 3.40 & 1.24 \\
\hline P13.KnowOrganizationType & 2.33 & 1.11 & 2.53 & 1.36 & 2.53 & 0.99 & 3.00 & 1.46 \\
\hline P14.KnowOccupation & 2.20 & 1.21 & 2.33 & 1.11 & 2.53 & 1.25 & 3.07 & 1.28 \\
\hline P15.PreferOrganization & 2.00 & 0.85 & 1.87 & 1.36 & 2.13 & 1.19 & 2.47 & 1.55 \\
\hline P16.PreferPosition & 2.33 & 1.05 & 2.53 & 1.25 & 2.27 & 1.16 & 2.93 & 1.39 \\
\hline P17.SpecificJob & 3.27 & 0.80 & 3.00 & 0.85 & 3.67 & 0.82 & 3.67 & 0.98 \\
\hline P18.OrganizationsTypes & 2.87 & 1.13 & 2.67 & 1.18 & 3.07 & 0.96 & 3.27 & 1.10 \\
\hline P19.SpecificOccupatio & 3.00 & 1.20 & 3.07 & 1.33 & .67 & 0.82 & 3.40 & 1.12 \\
\hline P20.JobsCongruentInterests & 3.9 & 0.80 & 3.47 & 0.92 & 3.60 & 0.99 & 3.53 & 0.99 \\
\hline P21SpecificOrganization & 3.07 & 0.80 & 2.33 & 1.29 & 3.00 & 1.07 & 2.93 & 1.22 \\
\hline P22.OccupationsRelatedInt & 3.47 & 0.83 & 3.53 & 0.99 & 3.60 & 0.83 & 3.73 & 1.22 \\
\hline P23.DecideWhatToDo & 6.27 & 0.70 & 4.67 & 1.80 & 6.27 & 0.70 & 4.53 & 2.00 \\
\hline P24.DecideOccupation & 5.27 & 1.33 & 4.40 & 1.59 & 5.33 & 1.29 & 4.27 & 1.87 \\
\hline P25.DecideSpecificJob & 4.80 & 1.52 & 4.00 & 1.69 & 4.73 & 1.62 & 3.80 & 1.74 \\
\hline P26.DecideSpecificOrg & 3.07 & 1.67 & 2.67 & 1.80 & 3.33 & 1.95 & 2.53 & 1.85 \\
\hline
\end{tabular}


A paired-samples t-test was conducted to compare pretest and post-test mean scores for all participants in CEPI as the persuasion stage. There was significant difference in scores between pre-test $(\mathrm{M}=4.35, \mathrm{SD}=0.44)$ and post-test $(\mathrm{M}=4.53$, $\mathrm{SD}=0.45)$ of PCLC with $\mathrm{t}(29)=-3.113, \mathrm{p}=.004$. These results suggest that our intervention affected students' career exploratory plans and intentions as persuasion. Specifically, our results propose that after students engage with data visualizations, their persuasion as their level of commitment in career exploration and seeking help is raised. Regarding students' career exploration survey in the persuasion stage (see Table 4, items P6 to P26), on average, students showed their high intention that they will investigate career possibilities, will go to various career orientation programs, will obtain information on specific jobs or companies and the labor market and will seek information on specific areas of career interest over the next 3 months. However, on average, students were not very sure about the type of job that is best for them or the type of organization they want to work for, or the occupation they want to enter (see Table 4, items P12 to P14). On the other hand, on average, students were satisfied with the amount of information they had on specific jobs and occupations they are interested in, types of organizations that will meet their personal needs, and occupations related to their interests and abilities. In terms of decisional stress level, students, on average, found deciding about an occupation, job, or a specific organization was one of the most stressful issues they had (see Table 4, items P23 to P26).

A paired-samples t-test was conducted to compare pretest and post-test mean scores for all participants in CEPI as the persuasion stage. There was significant difference in scores between pre-test $(\mathrm{M}=3.21, \mathrm{SD}=0.263)$ and post-test $(\mathrm{M}=3.48, \mathrm{SD}=0.401)$ of PCLC with $\mathrm{t}(29)=-3.584, \mathrm{p}=.001$. These results suggest that our intervention had an effect on students' career exploration survey as persuasion. Specifically, our results suggest that after students engaged with data visualizations, their persuasion as their intention to investigate career-related information, students' confidence about their career choices, students' satisfaction with career-related information they had, and students' level of stress about their career decisions overall had significant improvement. Using independent samples t-tests, significant differences were found in pretest scores between the graphs $(\mathrm{M}=3.15, \mathrm{SD}=1.18)$ and tables $(\mathrm{M}=4.07, \mathrm{SD}=1.37)$ groups on the career exploration survey, decisional stress subscale scores with $\mathrm{t}(29)=-2.22, \mathrm{p}=0.017$, as well as significant differences in post-test scores between the graphs $(\mathrm{M}=3.08, \mathrm{SD}=1.57)$ and tables $(\mathrm{M}=4.22, \mathrm{SD}=1.74)$ groups on the career exploration survey, decisional stress subscale scores with $\mathrm{t}(28)=-2.41, \mathrm{p}=0.02$.

\subsection{Decision Stage}

In the decision stage, students reported on their perceptions of career exploration and ranked their major preferences. Table 5 summarizes the descriptive statistics regarding students' perceptions of the career exploration process. Regarding career learning perceptions in the decision stage, students on average thought learning about careers was interesting, useful, enjoyable, and fun.

Table 5. Perceptions of the career exploration process in the decision stage

\begin{tabular}{|c|c|c|c|c|}
\hline \multirow{3}{*}{$\begin{array}{c}\text { Time } \\
\text { Condition } \\
\text { Item }\end{array}$} & \multicolumn{4}{|c|}{ Post-test } \\
\hline & \multicolumn{2}{|c|}{ Graphs (n=15) } & \multicolumn{2}{|c|}{ Tables $(\mathrm{n}=15)$} \\
\hline & M & SD & M & SD \\
\hline D1.LearningCareersInteresting & 4.40 & 0.51 & 4.53 & 0.52 \\
\hline D2.LearningCareersBoring & 1.60 & 0.74 & 1.53 & 0.64 \\
\hline D3.LearningCareersUseful & 4.73 & 0.46 & 4.87 & 0.35 \\
\hline D4.LearningCareersEnjoyable & 4.07 & 0.59 & 4.07 & 0.70 \\
\hline D5.LearningCareersFun & 3.87 & 0.83 & 3.93 & 0.88 \\
\hline D6.LearnigCareersDifficult & 3.53 & 0.74 & 2.93 & 1.22 \\
\hline D7.LearningCareersChallenging & 3.13 & 1.06 & 2.93 & 1.10 \\
\hline
\end{tabular}

For representative quotes regarding how students found the visualizations useful for their career planning and perceptions about majors, see Table 6.

In addition, during the pre-and post-test, all of the students were asked to write down and rank their intended majors for their career and the occupational areas that they would like to work on after graduation as part of the major preference ranking survey (MPRS). Students could write up to four majors and occupational areas. We compared students' changes in intended majors and occupational areas (see Figure 2). Specifically, we investigated to see whether the stu- 
dents added new options, removed some of the options, or modified the ranking of their choices. Figure 2 clearly shows that about $57 \%$ of the students changed their major choice after the intervention, whereas $70 \%$ of them changed their occupational area choices after the intervention in the decision stage.

Table 6. Representative quotes about students' perceptions regarding the usefulness of the materials

Theme

The visualizations helped students to compare their potential majors.

The visualizations helped students make future career decisions and career planning.

The visualizations helped students change their perceptions about their potential majors.

The visualizations helped students reflect on their own career path.

The visualizations changed how students perceive different majors.
Representative Quote

"Yeah, I definitely did. I'm like, I never really looked at graphs when like trying to analyze like what I'd like to do and stuff like that. So I found that really helpful. Like just having like the information there that was definitely needed, and there wasn't any extra information. It was definitely super easy to understand, like just looking at it and just like having every single thing that you needed there and just like seeing all of it and especially, um, how it was from like just Purdue students and graduates. Like I really liked that I thought that was really helpful.”

“Um, yeah, I think that definitely they kind of opened my mind to see, um, like the ones that I'm really interested, like what's really like going to be like the long-term effects. Um, and to see like if I'm really gonna, you know, be interested in wanting to follow up with that. So, if it's like worth it or not. So yeah, I definitely think that this helped a lot.”

"Yeah. Perception I would think. Um, has changed cause um, yeah, going in, like when I think when you sent the email about like what two majors you were considering and I was like, okay, I'm definitely considering psychology but like kind of public relations, I wasn't like really sure. But with like seeing the data about, um, like getting able to like visually see it. I'm like a visual learner too. So getting to like, just like having it right in front of me, I'm like, okay, so these are the facts and I can like compare between the two. So that was cool. Okay."

"Yeah, I would say so. Um, again, going back to the salary and the, uh, employment, like those are things I knew coming in. Um, I think the graduate school, I would say in the kinesiology graduate rate, um, for student, well, yeah, graduate school rate was about as much as I thought it would be, but the unemployment rate was kind of concerning for the students. I was definitely like, well maybe it's because they didn't decided to go to graduate school and now maybe theyll eventually go back and try to get a job. But, uh, it didn't really surprise me that the students had a lower percentage of finding a job. Cause, uh, most companies want kinesiology students who have at least a master's. Eventually I think most of will want a PhD, which is definitely a lot of work. But I'm sure it'd be worth it.”

"Yes. Yeah, it’s helped me, um, definitely perceive psychological sciences differently. Um, cause that was my top choice and I think it sounds switched from marketing being my top choice, but yeah. Oh good.”

\section{Major Choice Statistics}

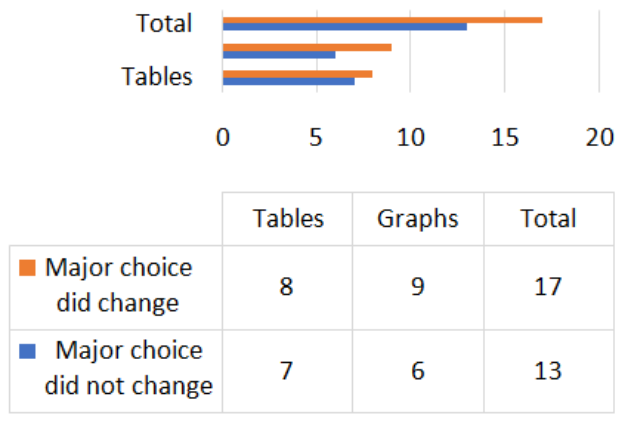

Number of Students

\section{Occupational Area Change Statistics}

\begin{tabular}{|c|c|c|c|}
\hline 0 & 5 & 10 & 20 \\
\hline & Tables & Graphs & Total \\
\hline $\begin{array}{c}\text { Occupational } \\
\text { area choice did } \\
\text { change }\end{array}$ & 9 & 12 & 21 \\
\hline $\begin{array}{l}\text { Occupational } \\
\text { area choice did } \\
\text { not change }\end{array}$ & 6 & 3 & 9 \\
\hline
\end{tabular}

Number of Students
Major choice did change

- Major choice did not change n Occupational area choice did change

n Occupational area choice did not change

Figure 2. Students' intended major and occupational area change statistics. 


\section{Discussion}

Career exploration is a complex and very challenging task, especially with the rise of interdisciplinary areas (Castellanos, 2018; Koech et al., 2016). Often, students are offered help through career advising, school career counseling, career decision-making courses, first-year exploratory studies programs, or peers' and parents' recommendations (Gordon \& Steele, 2015; Savickas, 2019). Although all of these strategies are helpful and have been found beneficial for career exploration, we suggest using historical post-graduation career data based on an individual's current preferences (i.e., targeted majors) to supplement traditional approaches to help in career exploration and eventual career decisions. In this study, students were given a pre and post-test to measure career learning competences reporting their level of awareness of their career-related learning competence, career exploratory plans, and intentions, and career exploration surveys to characterize their persuasion in the form of career exploration commitment, and perceptions of career learning and major preference ranking survey in the decision stage. This is one of the few interventions to explore how presenting historical post-graduation data influences career-related measures and helps with career decision-making, to the best of our knowledge. We found that students exposed to the historical post-graduation data regardless of the format presented had significant career learning and exploration growth in the awareness, persuasion, and decision stages. Specifically, our results suggest that when students engaged with historical post-graduation data, their preparedness for engaging in the process of career exploration, their level of commitment in career exploration and their intention of investigating career-related information, students' confidence about their career choices, student's satisfaction with career-related information they had, and students' level of stress about their career decisions overall had significant improvement.

Various career exploration studies have suggested that career exploration increases students' awareness about themselves and the world around them and helps them make better career decisions (Jiang et al., 2019; Lent et al., 2016, 2017). It is also accepted that career exploration improves an individual's career decision-making (Cheung \& Jin, 2016). Technological developments and tremendous amounts of data usage with the ultimate goal of improving decision-making have given rise to data-driven decision-making (DDDM) in numerous fields (Provost \& Fawcett, 2013). In career-related studies, DDDM has been shown to predict students' career choices upon graduation based on their behavior in and around the campus (Nie et al., 2016). Based on four types of behavior features such as professional skills, behavior regularity, economic status, and reading interests, Nie et al. (2016) evaluated the effectiveness of their data-driven framework and found that the extracted professional skills, behavior regularity, and economic status were significantly correlated with their career choices.

Moreover, our historical post-graduation data provides visualizations for trends within the last five years of graduation representing the percentage of students seeking education, seeking employment, continuing education, employed or others; average salaries over the last five years; average salaries of master's degree graduates; average salaries compared by degree level; most preferred graduate school locations by graduates; employment locations by the state during the year 2018, which was the most recent data they had; most preferred occupational areas during the year 2018; the number of internships they had during 2018; first 25 employers that class of 2018 students was working with; and finally data about the composite cost of living index during the first quarter of 2019 showing the cost of living index for all of the states in the USA. As far as we know, using historical post-graduation data to the extent in this paper for career decision-making and exploration has not been performed in the literature. Our study results suggest that career-related data visualizations can increase exploratory students' career knowledge and learning and make better future career decisions. Using historical post-graduation data from career outcome information from previous graduating classes as a strategy to support data-driven decision-making in career choice may be an effective means for promoting a variety of career exploration and decision-making outcomes for students.

\section{Conclusion, Limitations, and Future Work}

In this study, first-year exploratory studies students were offered information and guidance to explore multiple majors and occupations using various historical post-graduation data sources targeted to specific majors. The study showed that this intervention helped students improve their decision-making skills, explore their abilities, interests, and goals, and provided information about college majors, coursework, and careers to make informed career decisions. This strategy of using historical post-graduation data targeted to specific majors for career guidance, as far as we are aware, has not been done previously. The main results suggest that engaging students in career-related data affected outcome scores even in a short time. All of the students had higher scores in career learning and career exploratory plans and intention in the post-test than the pretest.

One of the limitations in the study was related to the time between the pre and post-test to digest career learning and 
intervention. Future studies might include a larger sample size in longitudinal study design. We may also improve the intervention aspects, such as using an interactive online application where students can explore careers without restriction. Although the stages of the diffusion of innovation process also include the stages of implementation and confirmation, the focus of this study was placed on the first initial stages to identify the effect of career-related data on students' decision-making processes. Future work is needed to further evaluate if students' career choices change, along with the reasons for those changes.

\section{Conflict of Interest}

The authors declare that there is no conflict of interest.

\section{References}

Athanasou, J. A. and Van Esbroeck, R. (2008). International handbook of career guidance. Springer.

Balasubramanyam, S., Usharani, D. P., Reddy, A. H. V., Swetha, D., Kumar, G. N. S., Anusha, K., and Ahammad, S. H. (2018). Selecting a College Academic Branch-a Design Decision Taking System for Student Career Selection. International Journal of Engineering \& Technology, 7(4.19), 323-328.

Betz, N. E. and Voyten, K. K. (1997). Efficacy and outcome expectations influence career exploration and decidedness. The Career Development Quarterly, 46(2), 179-189.

Brown, D. and Brown, D. (2012). Career information, career counseling, and career development. Pearson Boston, MA.

Castellanos, M. (2018). Examining Latinas' STEM career decision-making process: A psychosociocultural approach. The Journal of Higher Education, 89(4), 527-552.

Chaudhary, D., Prajapati, H., Rathod, R., Patel, P., and Gurjwar, R. (2019). Student Future Prediction Using Machine Learning. International Journal of Scientific Research in Computer Science, Engineering and Information Technology, 1104-1108. https://doi.org/10.32628/CSEIT1952300.

Cheung, R. and Jin, Q. (2016). Impact of a career exploration course on career decision making, adaptability, and relational support in Hong Kong. Journal of Career Assessment, 24(3), 481-496.

Fouad, N., Cotter, E. W., and Kantamneni, N. (2009). The effectiveness of a career decision-making course. Journal of Career Assessment, 17(3), 338-347.

Gati, I., Krausz, M., and Osipow, S. H. (1996). A taxonomy of difficulties in career decision making. Journal of Counseling Psychology, 43(4), 510.

Gordon, V. N. (2006). Career advising: An academic advisor's guide. John Wiley \& Sons.

Gordon, V. N., Habley, W. R., and Grites, T. J. (2011). Academic advising: A comprehensive handbook. John Wiley \& Sons.

Gordon, V. N. and Steele, G. E. (2015). The undecided college student: An academic and career advising challenge. Charles C Thomas Publisher.

Grant, T. L. (2019). How Students Choose a College: Understanding How College and Career Readiness Resources and Perceived Student Knowledge Influence College Choice [PhD Thesis]. Tarleton State University.

Hooley, T. (2012). How the internet changed career: Framing the relationship between career development and online technologies. Journal of the National Institute for Career Education and Counselling, 29(1), 3-12.

Hummel, H. G., Boyle, E. A., Einarsdóttir, S., Pétursdóttir, A., and Graur, A. (2018). Game-based career learning support for youth: Effects of playing the Youth@ Work game on career adaptability. Interactive Learning Environments, 26(6), 745-759.

Ikemoto, G. S. and Marsh, J. A. (2007). Cutting through the “Data-Driven” Mantra: Different Conceptions of Data-Driven Decision Making. Reprints. RAND Corporation.

Jääskeläinen, R. (2002). Think-aloud protocol studies into translation: An annotated bibliography. Target. International Journal of Translation Studies, 14(1), 107-136.

Jelks, S. M. and Crain, A. M. (2020). Sticking with STEM: Understanding STEM Career Persistence among STEM Bachelor's Degree Holders. The Journal of Higher Education, 1-27.

Jiang, Z., Newman, A., Le, H., Presbitero, A., and Zheng, C. (2019). Career exploration: A review and future research agenda. Journal of Vocational Behavior, 110, 338-356.

Kezar, A. and Gehrke, S. (2016). Faculty composition in four-year institutions: The role of pressures, values, and organizational 
processes in academic decision-making. The Journal of Higher Education, 87(3), 390-419.

Kirkner, T. and Levinson, J. (2012, September). Career Decision Making in a Brief Advising Context: Yes We Can! https://nacada.ksu.edu/Resources/Academic-Advising-Today/View-Articles/Career-Decision-Making-in-a-Brief-Advising-Co ntext-Yes-We-Can.aspx.

Koech, J., Bitok, J., Rutto, D., Koech, S., Okoth, J. O., Korir, B., and Ngala, H. (2016). Factors influencing career choices among undergraduate students in public universities in Kenya: A case study of university of Eldoret. International Journal of Contemporary Applied Sciences, 3(2), 50-63.

Lederman, D. (2018). Who Changes Majors? (Not Who You Think). Inside Higher Ed.

Lent, R. W., Ezeofor, I., Morrison, M. A., Penn, L. T., and Ireland, G. W. (2016). Applying the social cognitive model of career self-management to career exploration and decision-making. Journal of Vocational Behavior, 93, 47-57.

Lent, R. W., Ireland, G. W., Penn, L. T., Morris, T. R., and Sappington, R. (2017). Sources of self-efficacy and outcome expectations for career exploration and decision-making: A test of the social cognitive model of career self-management. Journal of Vocational Behavior, 99, 107-117.

Leu, K. (2017). Beginning College Students Who Change Their Majors within 3 Years of Enrollment. Data Point. NCES $2018-434$. National Center for Education Statistics.

Lewallen, W. C. (1995). Students Decided and Undecided About Career Choice: A Comparison of College Achievement and Student Involvement. NACADA Journal, 15(1), 22-30.

Li, M., Wu, W., Zhao, J., Zhou, K., Perkis, D., Bond, T. N., Mumford, K., Hummels, D., Chen, Y. V., and Potel, M. (2018). Careervis: Hierarchical visualization of career pathway data. IEEE Computer Graphics and Applications, 38(6), 96-105.

Mahajan, V. (2010). Innovation diffusion. Wiley International Encyclopedia of Marketing.

Mascia, M. B. and Mills, M. (2018). When conservation goes viral: The diffusion of innovative biodiversity conservation policies and practices. Conservation Letters, 11(3), e12442.

Nie, M., Yang, L., Ding, B., Xia, H., Xu, H., and Lian, D. (2016). Forecasting career choice for college students based on campus big data. Asia-Pacific Web Conference, 359-370.

Olamide, S. O. and Olawaiye, S. O. (2013). The factors determining the choice of career among secondary school students. The International Journal of Engineering and Science, 2(6), 33-44.

Provost, F. and Fawcett, T. (2013). Data science and its relationship to big data and data-driven decision making. Big Data, 1(1), 51-59.

Reese, R. J. and Miller, C. D. (2006). Effects of a university career development course on career decision-making self-efficacy. Journal of Career Assessment, 14(2), 252-266.

Rogers, E. M. (1962). (1995). Diffusion of innovations. New York: Free Press.

Rogers, E. M. (2010). Diffusion of innovations. Simon and Schuster.

Savickas, M. L. (1990). The career decision-making course: Description and field test. The Career Development Quarterly, 38(3), 275-284.

Savickas, M. L. (2019). Career counseling. American Psychological Association.

Schiersmann, C., Ertelt, B. J., Katsarov, J., Mulvey, H., and Weber, P. (2012). NICE Handbook for the Academic Training of Career Guidance and Counselling Professionals-Common Points of Reference. Im Internet Zugänglich: Ue-Career. Org/Download. Php.

Selingo, J. J. (2016). Two-thirds of college grads struggle to launch their careers. Harvard Business Review.

Stumpf, S. A., Colarelli, S. M., and Hartman, K. (1983). Development of the career exploration survey (CES). Journal of Vocational Behavior, 22(2), 191-226.

Verma, P., Sood, S. K., and Kalra, S. (2017). Student career path recommendation in engineering stream based on three-dimensional model. Computer Applications in Engineering Education, 25(4), 578-593.

Workman, J. L. (2015). Parental influence on exploratory students' college choice, major, and career decision making. College Student Journal, 49(1), 23-30. 


\section{Appendix 1: Pre- and Post-Questionnaire items/scales}

\section{Section A: Perceptions of Career Learning Competences (PCLC)}

The questions in this section are about career-related knowledge and understanding.

Please consider each of the statements below and indicate your level of agreement with it on a scale of 1 to 5, where: 1 means "I really disagree with this statement," 2 means "I disagree with this statement,” 3 means "I neither agree nor disagree with this statement," 4 means "I agree with this statement," and 5 means "I really agree with this statement."

A1 In finding out about careers, it is important for me to get a better understanding of myself and what I am like.

A2 I know which leisure activities are of most interest to me.

A3 I know which school subjects are of most interest to me.

A4 I know which career values are important to me in thinking about the kind of job that I would like to do in the future.

A5I can evaluate which job-related skills I am good at and those I am less good at.

A6I know which career-related personal attributes are most typical of me.

A7 I have a good understanding of the features of jobs that are of interest to me.

A8 I have a good understanding of how jobs differ with respect to the types of people who do these jobs and the features and skills involved in the job.

A9I am able to evaluate advice I am given about careers.

A10 It is important to think about how I can find a job that matches my interests.

\section{Section B: Career Exploratory Plans or Intentions (CEPI)}

In this section, you are asked about your Career exploratory plans and intentions.

Please consider each of the statements below and indicate your level of agreement with it on a scale of 1 to 5 , where: 1 means "I really disagree with this statement”; 2 means "I disagree with this statement”; 3 means "I neither agree nor disagree with this statement”; 4 means "I agree with this statement," and 5 means "I really agree with this statement"

B11 I intend to spend more time learning about careers than I have been.

B12 I plan to talk to lots of people about careers.

B13 I am committed to learning more about my abilities and interests.

B14 I intend to get all the education I need for my career choice.

B15 I plan to talk to advisors and counselors in my college about career opportunities for different majors.

Section C: Career Exploration Survey (CES)

In this section, you are asked about your career exploration.

Please consider each of the statements below and indicate your response level with a scale of 1 to 5 , where: 1 means "little"; 2 means "somewhat"; 3 means "a moderate amount"; 4 means "a substantial amount," and 5 means "a great deal." To what extent are you going to behave in the following ways over the next 3 months?

\section{Environment exploration:}

C16 Will investigate career possibilities.

C17 Will go to various career orientation programs.

C18 Will obtain information on specific jobs or companies.

C19 Will initiate conversations with knowledgeable individuals in my career area.

C20 Will obtain information on the labor market and general job opportunities in my career area.

C21 Will seek information on specific areas of career interest.

\section{Focus:}

Please consider each of the statements below and indicate your response level with a scale of 1 to 5 , where: 1 means "Not too sure" to 5 means "Very sure." How sure are you?

C22 That you know the type of job that is best for you?

C23 That you know the type of organization you want to work for?

C24 That you know exactly the occupation you want to enter?

C25 In your preference for a specific organization?

C26 In your preference for a specific position?

\section{Satisfaction with Information:}

Please consider each of the statements below and indicate your response level with a scale of 1 to 5 , where: 1 means "Not satisfied" to 5 means "Very satisfied." How satisfied are you with the amount of information you have?

C27 The specific job in which you are interested? 
C28 The types of organizations that will meet your personal needs?

C29 The specific occupation in which you are interested?

C30 Jobs, that are congruent with your interests and abilities?

C31 The specific organization in which you are interested?

C32 The occupations that are related to your interests and abilities?

\section{Decisional Stress:}

Please consider each of the statements below and indicate your response level with a scale of 1 to 7 , where: 1 means "Insignificant compared to other issues with which I have had to contend" to 4 means "about equal to other significant issues" and 7 means "One of the most stressful issues with which I have had to contend." How much undesirable stress have the following caused you relative to other significant issues with which you have had to contend?

C33 Deciding what I want to do.

C34 Deciding on an occupation.

C35 Deciding on a specific job.

C36 Deciding on a specific organization.

C34 Deciding on an occupation.

C35 Deciding on a specific job.

C36 Deciding on a specific organization.

\section{Section D: Perceptions of Career Learning (PCL)}

In this section, you are asked about your views on learning about careers. Please consider each of the statements below and indicate your level of agreement with it on a scale of 1 to 5, where: 1 means "I really disagree with this statement"; 2 means "I disagree with this statement”; 3 means "I neither agree nor disagree with this statement”; 4 means "I agree with this statement," and 5 means "I really agree with this statement"

D1 Learning about careers is interesting

D2 Learning about careers is boring

D3 Learning about careers is useful

D4 Learning about careers is enjoyable

D5Learning about careers is fun

D6 Learning about careers is difficult

D7 Learning about careers is challenging

\section{Appendix 2: Students' Preferred Two Majors}

\begin{tabular}{|c|c|c|}
\hline Student \# & Major 1 & Major 2 \\
\hline $\mathrm{S} 1$ & Industrial Management & Industrial Engineering Technology \\
\hline $\mathrm{S} 2$ & Computer Engineering/Electrical Engineering & Computer Science \\
\hline S3 & Accounting & Management \\
\hline S4 & Computer Engineering & Pre-Flight \\
\hline S5 & Elementary Education & Marketing \\
\hline S6 & Nursing & Kinesiology \\
\hline S7 & Social Studies Education & Kinesiology \\
\hline S8 & Mechanical Engineering Technology & Construction Management Technology \\
\hline S9 & Psychological Sciences & Sales and Marketing \\
\hline $\mathrm{S} 10$ & Computer and Information Technology & Computer Science \\
\hline $\mathrm{S} 11$ & Pre- Physician's Assistant and a minor in psychology & Health Sciences with a concentration in Pre-Med \\
\hline S12 & Psychology & Public Relations \\
\hline $\mathrm{S} 13$ & Accounting & Data sciences \\
\hline S14 & Construction Management & Marketing \\
\hline $\mathrm{S} 15$ & Health Sciences & Animal Sciences \\
\hline
\end{tabular}




\begin{tabular}{|c|c|c|}
\hline S16 & Industrial Engineering & Economics \\
\hline S17 & Nursing & Pre-Physician’s Assistant \\
\hline S18 & Brain and Behavioral Sciences & Political Science \\
\hline S19 & Accounting & Economics \\
\hline S20 & kinesiology & Nursing \\
\hline S21 & Economics & Marketing \\
\hline S22 & General Management & Accounting \\
\hline S23 & Engineering management through Multidisciplinary engineering & Industrial management \\
\hline S24 & Kinesiology & Forestry \\
\hline S25 & kinesiology & public health \\
\hline S26 & organizational leadership & international business \\
\hline S27 & Environmental and Ecological Engineering & Biology \\
\hline S28 & Animal Science & Biology \\
\hline S29 & Financial Counseling and Planning & Selling and Sales Management \\
\hline S30 & Construction Management Technology & Civil Engineering \\
\hline
\end{tabular}

